\title{
Article \\ Motivation, Stress and Impact of Online Teaching on Italian Teachers during COVID-19
}

\author{
Giusi Antonia Toto * (D) and Pierpaolo Limone \\ Department of Humanistic Studies, University of Foggia, 71100 Foggia, Italy; pierpaolo.limone@unifg.it \\ * Correspondence: giusi.toto@unifg.it
}

check for

updates

Citation: Toto, G.A.; Limone, P. Motivation, Stress and Impact of Online Teaching on Italian Teachers during COVID-19. Computers 2021, 10,75. https://doi.org/10.3390/ computers10060075

Academic Editors: Antonio

Sarasa Cabezuelo,

Covadonga Rodrigo San Juan and Santi Caballé

Received: 30 April 2021

Accepted: 4 June 2021

Published: 11 June 2021

Publisher's Note: MDPI stays neutral with regard to jurisdictional claims in published maps and institutional affiliations.

\begin{abstract}
The use of digital technology as the only communication and relationship channel in work, school and social contexts is bringing out dynamics that are sometimes in contrast with each other. The purpose of this article is to investigate the impact of digital technology on teachers' school practices in the context of COVID-19. This impact was studied in relation to the constructs of motivation, perceived stress, sense of self-efficacy and resistance to/acceptance of technologies. This study examined the role played by the massive and coercive use of digital technologies (and the relationship with innovation and change) in predicting motivation and perceived stress among teachers. To this end, the impact of digital technologies on motivation and perceived stress were explored in the sample. A questionnaire consisting of three scales was administered to 688 Italian school teachers of all educational levels (from childhood to upper-secondary school), who completed a socio-demographic section, a section on the scale of the impact of technology and distance learning, a perceived stress scale and items on motivation and professional development. Descriptive and inferential analyses were applied to the data. Key findings indicated that the impact of digital technologies during the pandemic negatively correlates with both perceived stress and motivation. Practical implications were suggested to help teachers develop functional coping styles to cope with technological changes in work and life contexts.
\end{abstract}

Keywords: professional vision; motivation; stress; digital learning; COVID-19

\section{Introduction}

Themes of the perception and professional vision of teachers have been consolidated as a specific realm of study in the last 30 years [1]. In the European context, the demand for digital skills within school contexts is determined by the development of the eight key skills (including digital literacy) and the DigCompEdu model for educators, which encourages the acquisition of meta-skills (learning to feel professional or learning to act with the media) that mediate their relationship with pupils [2,3]. This theoretical model involves the development of three fundamental components-awareness, reflexivity and cooperation - in the digital and pedagogical vision. The initial training of teachers is increasingly oriented and consolidated towards the use of information and communication technology (ICT) in contemporary teaching and teaching practice [4]. In fact, media education provides three possible applications of digital technology at school: (1) full online teaching, (2) hybrid teaching and (3) digitally mediated teaching. The first model is linked to distance training and e-learning, which were strongly implemented during the COVID-19 pandemic [5]. The second is still experimental in an Italian context (expected to be adopted in the post-COVID phase) and involves the use of moments and models of in-person teaching suitably alternated with those of online teaching [6]. The third is the more traditional model of digital technologies at school, which involves the instrumental use of technology that supports and enriches the frontal lesson [7] (essentially designed face-to-face). The scientific evidence reported in the meta-analysis by Bernard [8] shows that blended learning produces greater effects on students in terms of interactions with 
teachers, peers and with the content of the lesson taught in the classroom. Subsequent and application studies [9] have shown that the use of a mixed teaching model (online and face-to-face) is significantly associated with higher learning performance of students in the Science, Technology, Engineering and Mathematics (STEM) disciplines than traditional classroom practice. The contemporary debate stimulated by the COVID-19 pandemic has expanded research into unique full-online teaching practices during the pandemic (with a huge development of trials) and the future of this practice post-COVID that could result in a teaching hybrid. In the European context, the most unexpected scenarios are emerging. For example, English universities are experimenting with alternative solutions for students who do not have access to the Internet at home and the Charles III University of Madrid will carry out practical lessons in person and theoretical lessons online. Distance teaching for many universities, including those in Italy, has marked the loss of many economic gains [10]. The change of perspective described here manifests the need to move towards a social analysis of the impact of technology on the working life of the subjects and to describe the change taking place that determines the effects on professional well-being/malaise. Although paradigmatically discordant, the succession of different models is a testament to the construction of a professional paradigm oriented towards professional competence and well-being [11]. The five constituent components of wellbeing, in fact, turn out to be self-esteem, self-determination, positive emotions, optimism and resilience, which will characterise and direct subsequent research developments. The theme of teacher motivation is deeply felt by school governance boards and leadership because the motivation of teachers is reflected in the motivation of students [12,13]. These approaches are intended to encourage greater interaction with students and enhance selfdetermination, promote structured collaborative learning processes and reduce the number of traditional lessons. One of teachers' main concerns is to keep students' motivation high. However, education has one of the highest levels of stress compared to other professional groups and educators [14] often declare that they want to leave their profession. The context of the pandemic has made educational relationships with students even more intangible and has complicated this dynamic. A thriving field of study concerns the stress related to the use of digital technologies caused by a lack of training in the use of the technologies or by teachers' resistance to adopting them [15].

Influenced by Bandura's [16] social cognitive theory, and dissatisfied with previous models, Compeau and Higgins [17] developed a theory of human behaviour applied to the use of new technologies. Although in the first place the theory was devised to test acceptance of the use of the PC, subsequent studies [18] have shown that it is also easily usable in the field of communication technologies in general (Figure 1). The dimensions investigated concern the expectations of results in terms of both performance and interiority. The former refers to the consequences of one's behaviour in terms of professional results (outcome expectations); the latter, on the other hand, affects self-esteem and the sense of personal fulfilment. The dimension of computer self-efficacy, which crosses all sociocognitivist interpretative models, represents the subject's own assessment of the use of technology to skilfully accomplish a specific task. Affect is the individual's preference to experience a certain behaviour, and finally, anxiety, i.e., the induction of strong anxious or emotional reactions, is a reaction to the use of a specific technology [19]. The antecedents of outcome expectations and self-esteem are found in the encouragement of others, other uses and support. The process described in the model is aimed at the use of digital technology. 


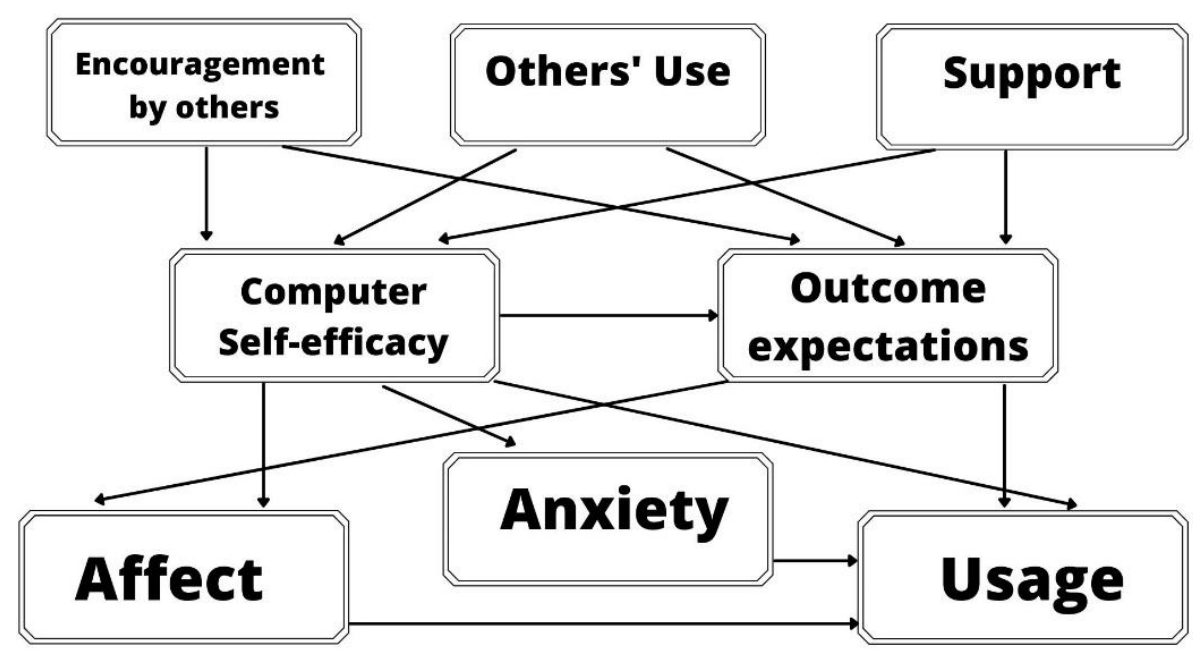

Figure 1. Social Cognitive Theory. Adapted with permission from ref. [17]. Copyright 2021 M I S Quarterly.

Bandura (and socio-cognitivist theorists in general) argues that, even in work contexts, subjects build their beliefs of self-efficacy by interpreting multiple inputs; experience of well-developed skills are one of the main sources of information for subjects to feel self-effective (and competent). In fact, teachers engage in training and didactic activities, interpret the results obtained and develop beliefs that will guide their choices and future actions. Usually, they persevere in activities in which they perceive themselves to be most effective and abandon those at which they consider themselves to be unsuccessful [20].

\section{The Study and Its Contexts}

The purpose of this research work was to analyse the motivation, stress perceived and impact and performance expectation of teachers in distance learning. The research hypothesis concerns the relationship and mutual influence between these three variables, especially in relation to the effects on the professional vision and the professionalism of teachers. The continuation of the COVID-19 pandemic in 2021 has made digital education the privileged channel for providing teaching in schools of all levels worldwide. An educational and social phenomenon of this magnitude has stimulated the interest of psychologists and pedagogues on learning problems related to distance learning and the motivation and professional competence of teachers working in this area. Experiments in online, hybrid and mixed training have been carried out for years, with the focus aimed at measuring their positive and negative effects on students in terms of learning effectiveness [21]. The COVID-19 pandemic has caused a profound change in the professional modality of teachers, as well as perceptions of self-efficacy and motivation in the use of online teaching. In this context, the University of Foggia has experimented with a work model that facilitates the first-person experimentation (by teachers) of innovative teaching methodologies linked to media education, gamification and knowledge transfer in the context of their daily professional practice. The monitoring of these three dimensions represents a fundamental step for the future of online and hybrid teaching within schools. The research is developed in the Italian context, where the specialisation course of teachers is online and groups teachers on a national scale; students therefore belong to all areas of Italy (67\% from southern Italy). The 10-year-old University of Foggia is a leader in distance learning and has provided all teacher training completely online (including workshops and internships) since March 2020, proposing for the third time a specialisation course for teachers $(n=688)$.

The interviewed teachers actually received a dual treatment: (1) trainers who delivered lessons, each in their own grade of school, and (2) students of a specialisation course carried out completely online (lessons, workshops and internships). This study was developed in relation to a questionnaire built on three scales: a scale on the impact of online teaching, 
a scale of stress perceived by students in the virtual room (validated in the context of COVID-19) and the expectation of performance and professional development of teachers. The interviewees were an adult population, coming from different areas of Italy, with an extensive training course behind them, and intrinsically motivated by the specificity of the care profession they were about to undertake and extrinsically by their attendance of a course that 'rewards' them with direct access to the profession and employability.

The data were broken down by demographic profile, response processing and educational level (childhood, primary school, lower-secondary school or upper-secondary school). The data was provided via Google Forms in March 2021 during the third wave of the COVID-19 state of emergency. Using the online form made it possible to receive results in real time and quickly view a summary.

The final version of the questionnaire, in addition to demographic questions about gender, school level, years of teaching, experience, work situation and others, also presented 26 Likert-type questions regarding the previous three scales with which the user could express various levels of agreement or disagreement (a copy of the questionnaire in Italian is available in Supplementary Materials).

An initial demographic analysis confirms research on gender differences that demonstrates that in the lower levels of education (childhood, primary), males represent only $1.1 \%$ of respondents for primary education and $4.4 \%$ for childhood. The percentage reaches $28-30 \%$ in lower and upper secondary schools. The average age was over 42 for kindergarten, over 40 for primary, 36.1 for middle school, and 37.9 in high school.

Participants were administered a self-report survey, including a sociodemographic scale and the following questionnaires:

(i) The online teaching-learning questionnaire measures the challenges faced in online teaching-learning, teacher-trainees' proposals for effective online teaching-learning and students' preferred way of conducting the course [22]. Background information provided by respondents measured variables including gender and the curriculum. The learning impact of online teaching and the challenges of online teaching-learning was measured through items that contained Likert scales of $1=$ strongly agree (SA), $2=$ agree $(\mathrm{A}), 3=$ undecided $(\mathrm{U}), 4=$ disagree $(\mathrm{D})$, and $5=$ strongly disagree (SD). The alpha values of 0.82 and 0.78 were found for the two constructs with Likert scales. There was internal consistency reliability test of items on the two constructs with the Likert scales using the Cronbach's Alpha $(\alpha)$ reliability analysis measures. However, Ghazali [23] indicated that the alpha value of 0.60 is also considered acceptable. This study attained the alpha values of 0.82 and 0.78 on the two constructs with the Likert Scales.

(ii) The Perceived Stress Scale (PSS) of Sheldon Cohen [24]. The scale consists of ten questions that are used to measure the perception of stress experienced by the participants over the past month. It includes a 5-point Likert scale that capture responses ranging from never to very often [25]. Total mean scores of 0-13 are considered to be low stress, 14-26 indicate moderate stress and 27-40 indicate high stress. The PSS is an easily and widely used tool with acceptable psychometric properties [26]. Across diverse conditions, researchers report relatively satisfactory reliability estimates for scores on the 14- and 10-item forms. For example, Roberti et al. [27] reported reliability estimates of 0.85 and 0.82 in a university sample for scores on the perceived helplessness and perceived self-efficacy scales, respectively.

(iii) The teacher motivation scale section, career development, consists of twelve items scored on a five-point Likert scale (from $1=$ not at all true of me to $5=$ very true of me) [28]. Sample items are: "When reading for a course, I make up questions to help focus my reading"; "I try to change the way I study in order to fit the course requirements and the lecturer's teaching style". In the current study, the scales showed adequate levels of reliability (Cronbach's alpha $=0.66)$. From the Teacher Motivation Framework of Analysis described in Section 3, a 98-question questionnaire was created and sent to 19 SC COs. The19 SC COs were not selected randomly, but 
rather on the basis of the type of SC Basic Education programming they were involved in. The survey was opened 15 April and closed on 29 April. Cos were given the option of completing the survey online via SurveyMonkey or via Microsoft Word attachment. Of the 19 COs contacted, 16 responded: from Afghanistan, Bangladesh, Bolivia, Egypt, El Salvador, Ethiopia, Haiti, Kyrgyzstan, Malawi, Mali, Mozambique, Nepal, Nicaragua, the Philippines, Tajikistan and Uganda.

In this study, forward translation of all questionnaires, from English into Italian, was performed by an English native speaker. The discrepancies existing in the Italian and in the back-translations were then discussed with the authors until consensus was reached.

\section{The Triadic Model}

All data were processed in IBM's statistical software SPSS, version 25. Before the main analysis, data were screened for univariate and multivariate outliers. Z-scores were used as the criterion for detection of univariate outliers. More precisely, all participants that had $z$-score higher than +3 or lower than -3 on one or more target variables were removed from further analyses. Seven univariate outliers were detected and removed from the data set. The criterion for detection of multivariate outliers was the Mahalanobis distance. No multivariate outliers were detected in the data set. The final sample had 688 participants.

In the next step, skewness and kurtosis of all target variables was inspected in order to determine whether the data were normally distributed. The results have shown that both skewness and kurtosis of all target variables (impact on online teaching, stress and motivation) were in the -1 to +1 range; hence, we may conclude that all variables were normally distributed (Table 1).

Table 1. Descriptive statistics.

\begin{tabular}{|c|c|c|c|c|}
\hline & Descriptives & & Statistic & Std. Error \\
\hline \multirow{13}{*}{ Impact on Online Teaching Total } & \multirow[b]{3}{*}{ 95\% Confidence Interval for Mean } & & 12.7674 & 0.15742 \\
\hline & & Lower Bound & 12.4584 & \\
\hline & & \multirow[t]{11}{*}{ Upper Bound } & 13.0765 & \\
\hline & $5 \%$ Trimmed Mean & & 12.6059 & \\
\hline & Median & & 12.0000 & \\
\hline & Variance & & 17.049 & \\
\hline & Std. Deviation & & 4.12907 & \\
\hline & Minimum & & 6.00 & \\
\hline & Maximum & & 26.00 & \\
\hline & Range & & 20.00 & \\
\hline & Interquartile Range & & 5.00 & \\
\hline & Skewness & & 0.555 & 0.093 \\
\hline & Kurtosis & & 0.027 & 0.186 \\
\hline \multirow{13}{*}{ Stress Total } & \multirow{3}{*}{ 95\% Confidence Interval for Mean } & \multirow{13}{*}{$\begin{array}{l}\text { Lower Bound } \\
\text { Upper Bound }\end{array}$} & 27.2049 & 0.30936 \\
\hline & & & 26.5975 & \\
\hline & & & 27.8124 & \\
\hline & $5 \%$ Trimmed Mean & & 27.0287 & \\
\hline & Median & & 26.0000 & \\
\hline & Variance & & 65.846 & \\
\hline & Std. Deviation & & 8.11455 & \\
\hline & Minimum & & 10.00 & \\
\hline & Maximum & & 48.00 & \\
\hline & Range & & 38.00 & \\
\hline & Interquartile Range & & 12.00 & \\
\hline & Skewness & & 0.323 & 0.093 \\
\hline & Kurtosis & & -0.652 & 0.186 \\
\hline
\end{tabular}


Table 1. Cont

\begin{tabular}{|c|c|c|c|c|}
\hline \multicolumn{3}{|c|}{ Descriptives } & \multirow{2}{*}{$\begin{array}{c}\text { Statistic } \\
28.9331\end{array}$} & \multirow{2}{*}{$\begin{array}{c}\text { Std. Error } \\
0.15983\end{array}$} \\
\hline \multirow{13}{*}{ Motivation Total } & Mean & & & \\
\hline & & Lower Bound & 28.6193 & \\
\hline & 95\% Confidence Interval for Mean & Upper Bound & 29.2470 & \\
\hline & 5\% Trimmed Mean & & 29.0061 & \\
\hline & Median & & 29.0000 & \\
\hline & Variance & & 17.576 & \\
\hline & Std. Deviation & & 4.19241 & \\
\hline & Minimum & & 17.00 & \\
\hline & Maximum & & 39.00 & \\
\hline & Range & & 22.00 & \\
\hline & Interquartile Range & & 6.00 & \\
\hline & Skewness & & -0.262 & 0.093 \\
\hline & Kurtosis & & -0.053 & 0.186 \\
\hline
\end{tabular}

\subsection{Reliability Analysis of the Questionnaires}

The initial questionnaire that measured the impact on online teaching consisted of seven items, and the Cronbach's alpha coefficient for complete scale was $\alpha=0.78$. However, the results of reliability analysis showed that the removal of one item from the questionnaire would improve the internal consistency of the scale. Item number one was removed because it was the only item in the scale that had a significantly lower item-total correlation in comparison to the item-total correlations of other items. When item number one was removed, the alpha coefficient increased to $\alpha=0.83$.

The initial questionnaire that measured stress consisted of 10 items, and the Cronbach's alpha coefficient for complete scale was $\alpha=0.88$. None of the items were removed from the scale because they all had approximately equal and optimal item-total correlation, and because the removal of any item would have lowered the alpha coefficient.

The initial questionnaire that measured motivation consisted of seven items, and the Cronbach's alpha coefficient for complete scale was $\alpha=0.66$. However, the results of reliability analysis showed that the removal of one item from the questionnaire would improve the internal consistency of the scale. The item that was named "item 22" was removed because it was the only item in the scale that had a significantly lower item-total correlation in comparison to the item-total correlations of other items. When the item named as "item 22" was removed, alpha coefficient increased to $\alpha=0.67$.

\subsection{Correlation}

Pearson's correlations were computed in order to test the significance of the relationships between impact on online teaching, stress and motivation (Table 2). The results of correlation analyses showed that the impact on online teaching was significantly correlated to motivation $r=-0.17, r^{2}=0.03, p<0.001$ and to stress $r=0.24, r^{2}=0.06, p<0.001$. The correlation between the impact on online teaching and motivation was negative, which means that when motivation was lower, the impact on online teaching tended to be higher. On the other hand, the correlation between the impact on online teaching and stress was positive, which means that higher stress was associated with the higher impact on online teaching. However, it must be emphasized that both correlation coefficients were very low. More precisely, impact on online teaching and motivation shared only $3 \%$ of variance, while impact on online teaching and stress shared only $6 \%$ of variance. Hence, it is highly probable that both correlations were significant only because the sample was large. Therefore, it is highly probable that both correlations were actually spurious. 
Table 2. Correlation among dimensions.

\begin{tabular}{|c|c|c|c|c|}
\hline \multicolumn{5}{|c|}{ Correlations } \\
\hline & & Motivation Total & Impact_on_Online_Teaching_Total & Stress Total \\
\hline \multirow{3}{*}{ Motivation Total } & Pearson Correlation & 1 & $-0.173^{* *}$ & $-0.216^{* *}$ \\
\hline & Sig. (2-tailed) & & 0.000 & 0.000 \\
\hline & $\mathrm{N}$ & 688 & 688 & 688 \\
\hline \multirow{3}{*}{$\begin{array}{l}\text { Impact on Online } \\
\text { Teaching Total }\end{array}$} & Pearson Correlation & $-0.173^{* *}$ & 1 & $0.235^{* *}$ \\
\hline & Sig. (2-tailed) & 0.000 & & 0.000 \\
\hline & $\mathrm{N}$ & 688 & 688 & 688 \\
\hline \multirow{3}{*}{ Stress Total } & Pearson Correlation & $-0.216^{* *}$ & $0.235^{* *}$ & 1 \\
\hline & Sig. (2-tailed) & 0.000 & 0.000 & \\
\hline & $\mathrm{N}$ & 688 & 688 & 688 \\
\hline
\end{tabular}

** Correlation is significant at the 0.01 level (2-tailed).

From the results reported in the two proposed tables, this study explores an important aspect of the use of technology in teaching, specifically the effects of distance learning on Italian teachers in terms of motivation and perceived stress. Compeau and Higgins's sociocognitive model of professional use and acceptance of technology within work contexts identifies anxiety, affect, self-efficacy and performance expectation as competing factors for digital technology use in teaching. The tool used in this study instead demonstrates (in the specific context of the COVID-19 pandemic) how motivation, stress and the impact of technology on learning and teaching have a significant value in the perceptions of Italian teachers. The construct of motivation is investigated in relation to professional development both in terms of skills acquisition and career progression. Perceived stress is measured in relation to teacher/student activities within the classroom, and the third scale investigates the advantages/disadvantages of web-enhanced (online) courses.

SEM (structural equation modelling) allows us to examine the relationships between the three independent variables with the dependent variable. In the case of the indirectly measured considerations observed in this study, the latent (i.e., indirectly measured) variables can be seen in the scheme proposed in Figure 2. The structural equation model (SEM) combines two tools within a single framework: confirmatory factor analysis and multivariate regression analysis. The CFA (confirmatory factor analysis) aims to build a model suitable for studying the relationships between the observed variables and the latent variables; that is, those constructs that are not observed but are derived from a combination of the observed variables. Regression analysis, on the other hand, aims to explain the random relationships between constructs. From the data, a triadic model of the professional vision of teachers in COVID-19 emerges, where motivation, stress and digital teaching are mediators, respectively, between career progression, perceptions and advantages/stress and the same professional vision. Compeau and Hiddigs' socio-cognitive theory model has also recently been associated with a line of studies on the acceptance of digital technology in teachers' school practice (UTAUT) [29]. Specifically, the intrinsic and extrinsic motivation factors of support from others (encouragement, use and support), stress (anxiety and emotion in general) and digital performance in general have strengthened the idea of using online teaching in school lessons. Individually analysed data collected by the three scales indicates that the interviewed sample showed high scores in all three dimensions: career desire, stress and the benefits of digital technologies (Figure 2). At the same time, the negative correlation between motivation and stress was confirmed $\left(-0.216^{* *}\right)$. As the impact of digital technologies increased, perceived stress also increased $\left(0.235^{* *}\right)$, and the original data of this research concerned the increase in the impact of technology, which decreased the motivation of the interviewees $\left(-0.173^{* *}\right)$. 


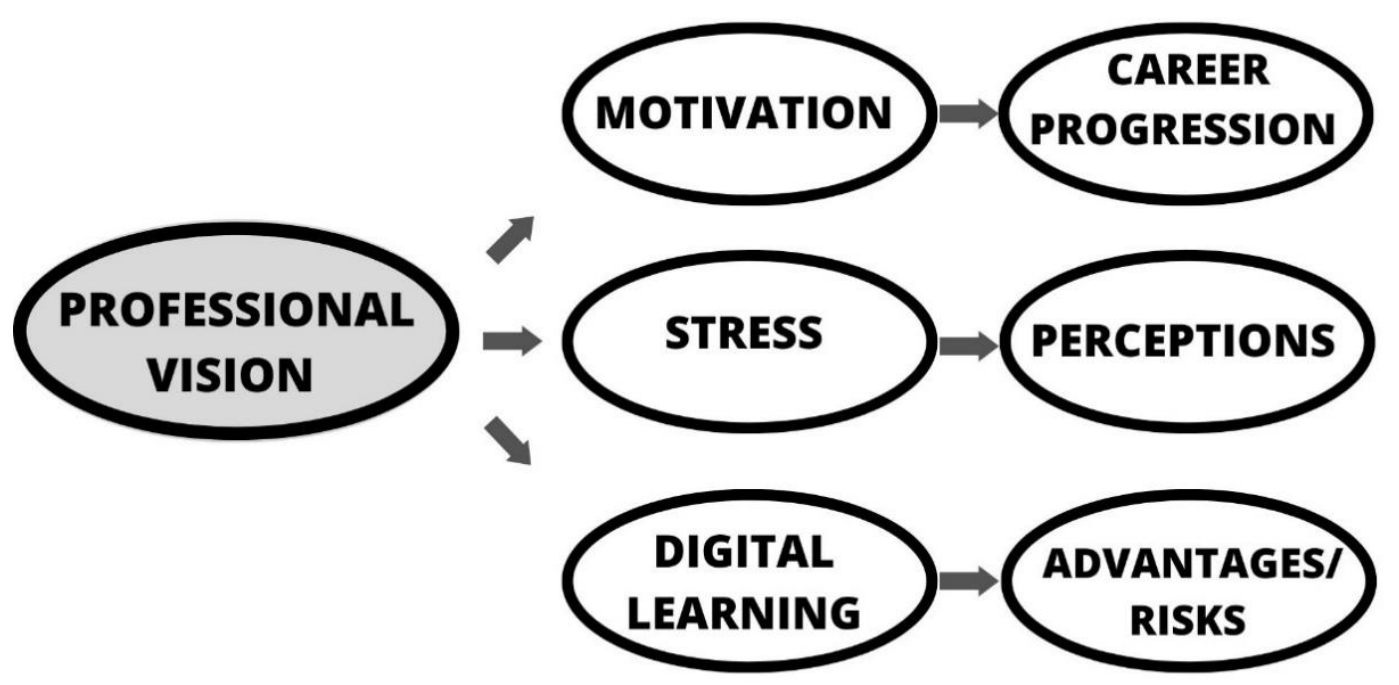

Figure 2. Model of professional vision in COVID-19.

Although online teaching was the only possible communication channel during the pandemic, the teachers on the course continued to practice it one year after its exclusive use; they experienced it as a demotivator and a source of stress and therefore, there is evidence of a possible refusal in the future use of online teaching. In higher education, learning environments are transforming to respond to new demands in the field of teaching methodologies. Everything is happening through the integrated use of technologies in educational paths, redesigning the space-time boundaries of learning thanks to the application of flexible teaching methodologies [30].

In the current historical period, it has been highlighted how the rapid transition from face-to-face teaching to DDA has strongly influenced teaching methods. Research on learning design has always emphasized the importance of developing teachers' skills related to devising pedagogically sound interventions on the basis of designed and sustainable teaching methodologies [31,32]. Therefore, there is a clear need for training interventions aimed at teachers to strengthen a design capacity that will guarantee quality teaching through the application of the most recent digital technologies [33,34]. In fact, in this initial phase of exploring technological tools, many educators have neglected the principles of collaborative teaching that require planning and organisation skills at work. Above all, these components are strategic for promoting social interactions and strengthening cooperative learning. Given that the world of digital didactic technologies is equipped with dialogic tools, teacher training should be aimed at better consolidation of the network affordances for quality technological didactic planning [35].

\section{Discussion and Conclusions}

The socio-cognitive model applied to digital technology in the professional practice of teachers is described as influencing three fundamental factors: personal, behavioural and socio-environmental. In this study, the three factors of motivation, stress and impact of the technology were operationalized. These factors influence each other, but contemporary research must understand their influences on teaching and learning. The factor of motivation investigated in this study is linked to the dimension of self-determination and the career prospects of teachers [36]. Perceived stress becomes a fundamental element in the analysis because it is linked both to the specificity of the COVID-19 period, which forced social isolation, and to the exclusive use of digital technology as a training and work channel [37].

The arduous process of integrating technologies into formal learning environments has rapidly accelerated during the COVID-19 pandemic. Virtual and immersive learning environments were the solution to the emergency phase for all levels of training. The slow integration process, however, requires a degree of digital competence on the part of teachers to guide policies and procedures in their own school. The process must be supported by 
planning and designing the training and education of teachers for the use of technology in their classrooms [38]. In the present study, the category of "students" captures participants in their double role as students in the training course and as teachers in their everyday professional practice. In the school and academic context, the emergency situation has had significant repercussions; prolonged closures and the sudden transmission and construction of content in online mode has had an impact on various levels. Onyema et al. [39] listed as major repercussions the renewed learning methods with the relative activation difficulties, the danger of social isolation and the increase in socio-economic inequalities deriving from the existing digital divide [40]. The consequences have been twofold for education professionals: on the one hand, the need for a quick transformation of teaching practices and personal styles of instruction has caused stress, and on the other, learning new teaching methods that will be useful in the future has provided motivation.

Teachers are among the key actors involved in academic rehabilitation. A study conducted by the Italian Society of Didactic Research (SIRD) found that their main problems were a perceived lack of preparation in dealing with this new modality, as well as the required total reorganisation of the didactics, which is associated with an excessive workload, both in terms of construction and timing. However, a study by Ardizzoni [41] highlighted that the use of educational technologies played a supportive role in the management of relational dynamics with students. Nevertheless, difficulties with devices and reaching all students, especially those in a fragile condition, remain unchanged.

On the other hand, it is hypothesised that the implementation of digital technologies has allowed educators to understand the potential associated with their use. It emerges that instruction through digital platforms motivates students to learn and optimises the classroom environment [42]. Teachers, therefore, have gradually reinvented the already consolidated teaching methods, and the most highly motivated teachers have taken part in training courses with a view to lifelong learning.

The process of including technology within the classroom context is never exhausted but goes hand in hand with technological evolution. In this picture, two competing dynamics emerge: the first, motivation, oscillates, according to socio-cognitive theory, between the expectation of performance and the attribution of value and self-efficacy. In fact, the self-determined teacher pursues the need for competence (since he/she is an expert and master of carrying out his/her task), the need for autonomy (his/her actions emerge from intrinsic motivation) and the need for a relationship (establish close emotional ties and attachment to significant subjects, i.e., colleagues and students) [43].

If it is true that motivation, stress and digital learning have direct effects on the professional vision of teachers, it is also true that the desire (and perspectives) of career development, the perceptions (and personal beliefs) of teachers and the knowledge of the risks and benefits of technologies within the teaching process have a secondary (and latent) effect on the profession of teaching. The importance of this second implication of the study allows us to reflect on what dimensions are necessary to act for a general improvement of professional vision. Although career prospects are linked to leadership and school governance, personal beliefs and knowledge of the risks/benefits of technologies require in-service training interventions that enhance performance in these areas [44].

When this process does not follow a linear development like that shown due to limiting beliefs, low self-esteem, limited sense of self-efficacy and lack of social support, it can become a source of stress for teachers, students and the whole social context. A maladaptive response to the change triggered by technologies in work (and school) contexts produces perceived stress on the part of teachers. The perceived stress more specifically concerns the lack of control and unpredictability rather than a relationship with real stressful events. The subjects are focused on what might happen and decide that a change to horrible conditions is inevitable. Among the negative effects of perceived stress in relation to technology (in addition to those related to psycho-physical well-being), is the structuring of dysfunctional coping mechanisms. The most evident phenomenon is represented by the resistance and non-acceptance of digital technology in teaching 
practice [45]. The COVID-19 pandemic has prompted the reinvention of university teaching. Academic institutions have had to reset their teaching practices so as to incorporate digital technologies, some of them for the first time. This sudden change has led to a number of problems in the use of an emergency type of distance learning, including technological infrastructure weakness, teacher inexperience and a perceived invasion of privacy in the home environment [46]. Furthermore, research by Bao [47] revealed that students were more concerned about the quality of internet connectivity, which is essential for both participation in synchronous lessons and exams. The teachers involved in this research declared that they preferred online lessons in asynchronous mode. The main problem is not related to the use of technological tools but to the lack of both structural and didactic preparation of the teachers themselves. Therefore, in many cases, remote teaching has resulted in the transfer of traditional frontal lessons to an online mode with little awareness of the design required to ensure effective learning in virtual teaching environments.

Future research perspectives could investigate precisely this dynamic linked to the construction of increasingly valid and effective tools for investigating motivation and perceived stress in relation to digital technologies and all the main changes affecting the world of education. In addition, it would be necessary to build intervention and prevention models in relation to the stress perceived by teachers that would lead to the educational success of their students and greater well-being within the classroom.

Supplementary Materials: The following are available online at https:/ / www.mdpi.com/article / $10.3390 /$ computers $10060075 /$ s1.

Author Contributions: Conceptualization, and The Study and Its Contexts: P.L.; The Triadic Model and Discussion and Conclusions: G.A.T. All authors have read and agreed to the published version of the manuscript.

Funding: This research received no external funding.

Institutional Review Board Statement: The study was conducted according to the guidelines of the Declaration of Helsinki and ap-proved by the Institutional Review Board of PhD trials, protocol code 30216-III.11 and approved on 30 January 2021.

Informed Consent Statement: Informed consent was obtained from all subjects involved in the study.

Data Availability Statement: The data presented in this study are available in article.

Conflicts of Interest: The authors declare no conflict of interest.

\section{References}

1. Keppens, K.; Consuegra, E.; De Maeyer, S.; Vanderlinde, R. Teacher beliefs, self-efficacy and professional vision: Disentangling their relationship in the context of inclusive teaching. J. Curric. Stud. 2021, 53, 314-332. [CrossRef]

2. Caena, F.; Redecker, C. Aligning teacher competence frameworks to 21st century challenges: The case for the European Digital Competence Framework for Educators (Digcompedu). Eur. J. Educ. 2019, 54, 356-369. [CrossRef]

3. Boccioni, S.; Earp, J.; Panesi, S. DigCompEdu. Il quadro di Riferimento Europeo Sulle Competenze Digitali dei Docenti; Istituto per le Tecnologie Didattiche, Consiglio Nazionale delle Ricerche (CNR), 2018. Available online: https://www.itd.cnr.it/doc/ DigCompEduITA.pdf (accessed on 7 June 2021).

4. Schmid, M.; Brianza, E.; Petko, D. Self-reported technological pedagogical content knowledge (TPACK) of pre-service teachers in relation to digital technology use in lesson plans. Comput. Hum. Behav. 2021, 115, 106586. [CrossRef]

5. Marek, M.W.; Chew, C.S.; Wu, W.C.V. Teacher experiences in converting classes to distance learning in the COVID-19 pandemic. Int. J. Distance Educ. Technol. 2021, 19, 40-60. [CrossRef]

6. Limone, P. Towards a hybrid ecosystem of blended learning within university contexts. In CEUR Workshop; Elsevier: Amsterdam, The Netherlands, 2021; p. 2817.

7. Tejasvee, S.; Gahlot, D.; Poonia, R.; Kuri, M. Digital Learning: A Proficient Digital Learning Technology Beyond to Classroom and Traditional Learning. In Advances in Information Communication Technology and Computing; Springer: Singapore, $2021 ;$ pp. 303-312.

8. Bernard, R.M.; Borokhovski, E.; Schmid, R.F.; Tamim, R.M.; Abrami, P.C. A meta-analysis of blended learning and technology use in higher education: From the general to the applied. J. Comput. High. Educ. 2014, 26, 87-122. [CrossRef]

9. Vo, H.M.; Zhu, C.; Diep, N.A. The effect of blended learning on student performance at course-level in higher education: A meta-analysis. Stud. Educ. Eval. 2017, 53, 17-28. [CrossRef] 
10. Semenzato, A. Alma mater- how the great European universities are trying to deal with the consequences of the pandemic. In Linkiesta; Linkiesta.it S.r.l.: Milan, Italy, 2020.

11. Toto, G.A.; Limone, P. New Perspectives for Using the Model of the Use and Acceptance of Technology in Smart Teaching. In International Workshop on Higher Education Learning Methodologies and Technologies Online; Springer: Cham, Switzerland, 2020; pp. 115-125.

12. Wang, H.; Hall, N.C.; Rahimi, S. Self-efficacy and causal attributions in teachers: Effects on burnout, job satisfaction, illness, and quitting intentions. Teach. Teach. Educ. 2015, 47, 120-130. [CrossRef]

13. Lin, M.-H.; Chen, H.-C.; Liu, K.-S. A Study of the Effects of Digital Learning on Learning Motivation and Learning Outcome. Eurasia J. Math. Sci. Technol. Educ. 2017, 13, 3553-3564. [CrossRef]

14. Abou-Khalil, V.; Helou, S.; Khalifé, E.; Chen, M.A.; Majumdar, R.; Ogata, H. Emergency Online Learning in Low-Resource Settings: Effective Student Engagement Strategies. Educ. Sci. 2021, 11, 24. [CrossRef]

15. Fernández-Batanero, J.M.; Román-Graván, P.; Reyes-Rebollo, M.M.; Montenegro-Rueda, M. Impact of Educational Technology on Teacher Stress and Anxiety: A Literature Review. Int. J. Environ. Res. Public Health 2021, 18, 548. [CrossRef] [PubMed]

16. Bandura, A. Social Foundations of Thought and Action; Prentice-Hall: Englewood Cliffs, NJ, USA, 1986; pp. $23-28$.

17. Compeau, D.R.; Higgins, C.A. Computer self-efficacy: Development of a measure and initial test. MIS Q. 1995, 19, 189-211. [CrossRef]

18. Venkatesh, V.; Bala, H. Technology acceptance model 3 and a research agenda on interventions. Decis. Sci. 2008, 39, 273-315. [CrossRef]

19. Compeau, D.; Higgins, C.A.; Huff, S. Social cognitive theory and individual reactions to computing technology: A longitudinal study. MIS Q. 1999, 23, 145-158. [CrossRef]

20. Barak, M. Science teacher education in the twenty-first century: A pedagogical framework for technology-integrated social constructivism. Res. Sci. Educ. 2017, 47, 283-303. [CrossRef]

21. Wu, J.Y.; Nian, M.W. The dynamics of an online learning community in a hybrid statistics classroom over time: Implications for the question-oriented problem-solving course design with the social network analysis approach. Comput. Educ. 2021, 166, 104120. [CrossRef]

22. Tsitsia, B.Y. Assessing Teacher-Trainees' Perceptions Regarding the Online teaching-learning mode of the Agricultural Science Course. Int. J. Educ. Res. 2020, 8, 111-124.

23. Ghazali, D. Kesahan dan Kebolehpercayaan Dalam Kajian Kuantitatif dan Kualitatif. J. Inst. Perguru. Islam 2008, 61-82.

24. Cohen, S. Psychosocial vulnerabilities to upper respiratory infectious illness: Implications for susceptibility to coronavirus disease 2019 (COVID-19). Perspect. Psychol. Sci. 2021, 16, 161. [CrossRef] [PubMed]

25. Deemah, A.A.; Sumayah, A.; Dalal, A. Perceived stress among students in virtual classrooms during the COVID-19 outbreak in KSA. J. Taibah Univ. Med Sci. 2020, 15, 398-403.

26. Taylor, J.M. Psychometric analysis of the ten-item perceived stress scale. Psychol. Assess 2015, 27, 90-101. [CrossRef]

27. Roberti, J.W.; Harrington, L.N.; Storch, E.A. Further Psychometric Support for the 10-Item Version of the Perceived Stress Scale. J. Coll. Counseling 2006, 9, 135-147. [CrossRef]

28. Guajardo, J. Teacher Motivation: Theoretical Framework, Situation Analysis of Save the Children Country Offices, and Recommended Strategies; Save the Children: Fair-Field, CT, USA, 2011.

29. Tan, P.J.B. Applying the UTAUT to understand factors affecting the use of English e-learning websites in Taiwan. Sage Open 2013, 3, 2158244013503837. [CrossRef]

30. Heilporn, G.; Lakhal, S.; Bélisle, M. An examination of teachers' strategies to foster student engagement in blended learning in higher education. Int. J. Educ. Technol. High. Educ. 2021, 18, 1-25. [CrossRef]

31. Linn, M.; Eylon, B.; Kidron, A.; Gerard, L.; Toutkoushian, E.; Ryoo, K.; Bedell, K.D.; Swearingen, A.; Clark, D.; Virk, S.; et al. Knowledge Integration in the Digital Age: Trajectories, Opportunities and Future Directions. In Rethinking Learning in the Digital Age: Making the Learning Sciences Count, 13th International Conference of the Learning Sciences (ICLS) 2018; International Society of the Learning Sciences: London, UK, 2018; Volume 2.

32. Canlon, E.; Anastopoulou, S.; Conole, G.; Twiner, A. Interdisciplinary Working Methods: Reflections Based on TechnologyEnhanced Learning (TEL). Front. Educ. 2019, 4, 134. [CrossRef]

33. Hodges, C.; Moore, S.; Lockee, B.; Trust, T.; Bond, A. The difference between emergency remote teaching and online learning. Educ. Rev. 2020, 27, 1-12.

34. Williamson, B.; Eynon, R.; Potter, J. Pandemic politics, pedagogies and practices: Digital technologies and distance education during the coronavirus emergency. Learn. Media Technol. 2020, 45, 107-114. [CrossRef]

35. Pérez-Paredes, P.; Guillamón, C.O.; Van de Vyver, J.; Meurice, A.; Jiménez, P.A.; Conole, G.; Hernández, P.S. Mobile data-driven language learning: Affordances and learners' perception. System 2019, 84, 145-159. [CrossRef]

36. Panisoara, I.O.; Lazar, I.; Panisoara, G.; Chirca, R.; Ursu, A.S. Motivation and Continuance Intention towards Online Instruction among Teachers during the COVID-19 Pandemic: The Mediating Effect of Burnout and Technostress. Int. J. Environ. Res. Public Health 2020, 17, 8002. [CrossRef]

37. Salikhova, N.R.; Lynch, M.F.; Salikhova, A.B. Psychological Aspects of Digital Learning: A Self-Determination Theory Perspective. Contemp. Educ. Technol. 2020, 12, ep280. [CrossRef] 
38. Toto, G.; Limone, P. From Resistance to Digital Technologies in the Context of the Reaction to Distance Learning in the School Context during COVID-19. Educ. Sci. 2021, 11, 163. [CrossRef]

39. Onyema, E.M.; Eucheria, N.C.; Obafemi, F.A.; Sen, S.; Atonye, F.G.; Sharma, A.; Alsayed, A.O. Impact of Coronavirus Pandemic on Education. J. Educ. Pract. 2020, 11, 108-121.

40. Cucco, B.; Gavosto, A.; Romano, B. How to Fight Against Drop Out and Demotivation in Crisis Context: Some Insights and Examples from Italy. In Radical Solutions for Education in a Crisis Context; Springer: Singapore, 2021; pp. 23-36.

41. Ardizzoni, S.; Bolognesi, I.; Salinaro, M.; Scarpini, M. Didattica a Distanza con le Famiglie: L'esperienza di Insegnanti e Genitori, in Italia e in Cina, Durante L'emergenza Sanitaria 2020. Uno Studio Preliminare. Infanzia, Famiglie, Servizi Educativi e Scolastici nel Covid-19; University of Bologna: Bologna, Italy, 2020; p. 71. (In Italian)

42. Tan, P.J.B.; Hsu, M.H. Developing a system for English evaluation and teaching devices. In Proceedings of the 2017 International Conference on Applied System Innovation (ICASI), Sapporo, Japan, 13-17 May 2017; pp. 938-941.

43. Sprenger, D.A.; Schwaninger, A. Technology acceptance of four digital learning technologies (classroom response system, classroom chat, e-lectures, and mobile virtual reality) after three months' usage. Int. J. Educ. Technol. High. Educ. 2021, 18, 1-17. [CrossRef]

44. Fan, R.-J.D.; Tan, P.J.B. Application of Information Technology in Preschool Aesthetic Teaching from the Perspective of Sustainable Management. Sustainbility 2019, 11, 2179. [CrossRef]

45. Bolatov, A.K.; Seisembekov, T.Z.; Askarova, A.Z.; Baikanova, R.K.; Smailova, D.S.; Fabbro, E. Online-Learning due to COVID-19 Improved Mental Health Among Medical Students. Med Sci. Educ. 2021, 31, 183-192. [CrossRef] [PubMed]

46. Bao, W. COVID-19 and online teaching in higher education: A case study of Peking University. Hum. Behav. Emerg. Technol. 2020, 2, 113-115. [CrossRef] [PubMed]

47. Liu, X.; Liu, J.; Zhong, X. Psychological State of College Students during COVID-19 Epidemic (3/10/2020). Available online: https: / / ssrn.com/abstract=3552814 (accessed on 7 June 2021). 